\title{
Model of Multiple Artificial Neural NETWORKS ORIENTED ON SALES PREDICTION AND Product Shelf Design
}

\author{
Alessandro Massaro, Valeria Vitti, Angelo Galiano \\ Dyrecta Lab, IT Research Laboratory, via Vescovo Simplicio, n. 45, 70014 Conversano \\ (BA), Italy
}

\begin{abstract}
In this paper the authors proposed different Multilayer Perceptron Models (MLP) of artificial neural networks (ANN) suitable for visual merchandising in Global Distribution (GDO) applications involving supermarket product facing. The models are related to the prediction of different attributes concerning mainly shelf product allocation applying times series forecasting approach. The study highlights the range validity of the sales prediction by analysing different products allocated on a testing shelf. The paper shows the correct procedures able to analyse most guaranteed results, by describing how test and train datasets can be processed. The prediction results are useful in order to design monthly a planogram by taking into account the shelf allocations, the general sales trend, and the promotion activities. The preliminary correlation analysis provided an innovative key reading of the predicted outputs. The testing has been performed by Weka and RapidMiner tools able to predict by MLP ANN each attribute of the experimental dataset. Finally it is formulated an innovative hybrid model which combines Weka prediction outputs as input of the MLP ANN RapidMiner algorithm. This implementation allows to use an artificial testing dataset useful when experimental datasets are composed by few data, thus accelerating the self-learning process of the model. The proposed study is developed within a framework of an industry project.
\end{abstract}

\section{KEYWORDS}

Visual Merchandising, Artificial Neural Networks, Times Series Forecasting, Weka, RapidMiner, Product Facing, Sales Prediction, Multiple ANN, Hybrid ANN Model.

\section{INTRODUCTION}

Visual Merchandising (VM) is characterized in literature by the following research topics [1]:

- perspective analysis of the of the shelf;

- relationship between the various parts of the displayed products;

- movement effect induced by allocation of products;

- harmony;

- colors and lights.

Other studies have shown how the visual aspect is relevant for the consumer choice about products allocated on a shelf [2]. 
The concept of VM is extended in literature by the study of the online visual merchandising (OVM) [3]-[4], by confirming that the analyses performed into a store are different if compared with e-commerce ones. For this reason the visual impact of a supermarket shelf could be a specific research topic of VM. Another interesting research topic correlated to $\mathrm{VM}$ is the customer clustering by data mining enabling business processes [5]. Also neurosciences have been applied in the field of VM, by studying sensory effects of the consumer in neuromarketing [6] which follows precisely the logic of artificial neural networks (ANNs). These ANNs have also been implemented in the marketing sector for forecasting and predictive analysis [7]. Recent studies have instead validated the neural network approach for forecasting of stock market price, showing how such networks can be a powerful tool for financial analysis [8]. Other studies on neural networks are in analysis of market shares [9]. These studies suggest the use ANNs also for VM applications. Some input variables useful for VM analysis are marketing information, environmental information [10], and customer information [11]. In the Global Distribution (GDO) field, ANNs have been applied in [12] to predict sales of fresh food products such as fresh milk. Other input variables useful for the shelf-space allocation analysis are product geometry, product orientation in the shelves [13], sales number, price, promotion percentage, shelf distance [14], and social trend [15]. In this direction data mining can support the shelf space allocation by applying different approaches [16]. Recent scientific papers have discussed the superior predictive properties of particular types of neural networks such as Deep Neural Networks (DNN) which are characterized by different data processing layers [17]. Other recent studies have shown the applicability of ANNs to the consumer model by means of the processing of customer loyalty and customer satisfaction variables [18]. Other researchers highlighted the importance the accuracy estimation about the reliability of the model [19]. Finally, in [20] researchers focused their attention on consumer behavior which can affect sales. Concerning GDO market basket analysis (MBA) represents a good tool for shelf planogram design and in general for business intelligence of supermarkets [21]. This last study suggests as in the proposed research to process data monthly thus orienting the planogram design on a medium period.

Following the main topics analyzed in state of the art will be implemented different ANN models able to process different attributes of supermarket orienting the research outputs on the product facing and planogram design. The proposed paper is structured as follow:

- description of the main specifications of the industry project;

- description of the dataset model and of the data pre-processing phase by explaining the attribute meaning and their importance in the analysis;

- data processing of different times series forecasting ANN Weka and RapidMiner models by interpreting different prediction outputs;

- definition of new hybrid model ANN Weka/RapidMiner models useful for the selflearning phase. 
International Journal on Soft Computing, Artificial Intelligence and Applications (IJSCAI), Vol.7, No.3, August 2018

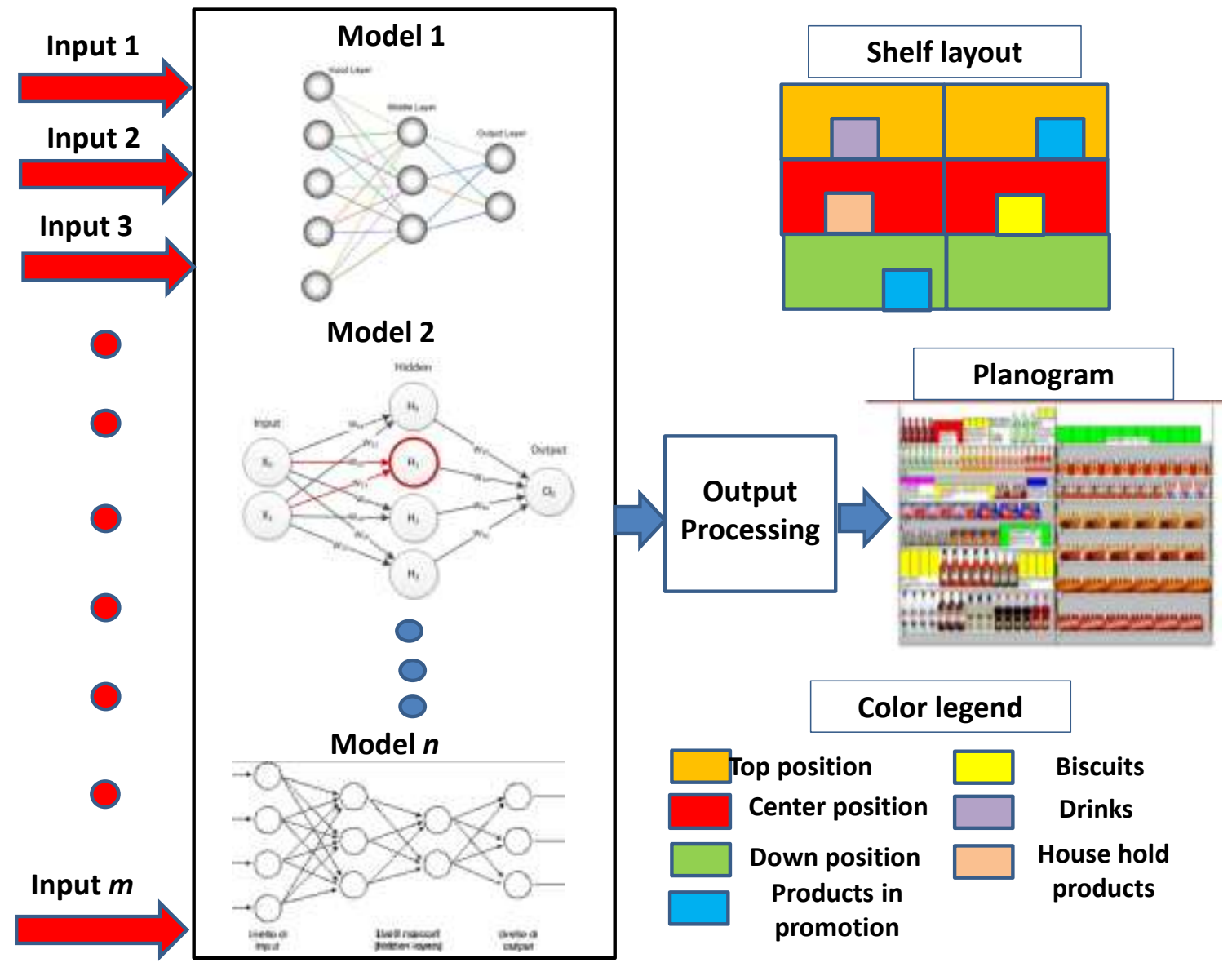

Figure 1. Main functional diagram of the project workflow: planograms constructed by multiple ANN outputs.

\section{PROJECT GOAL: SYSTEM ARCHITECTURE}

The industry project where the research has carried out concerns the development of different models based on the analysis of different ANN outputs oriented on the design of shelf layouts.

In Fig. 1 is illustrated the architecture of the proposed project defined by the following input and output specifications:

- $\quad \mathrm{m}$ number of inputs variables to process (attributes);

- $\quad \mathrm{n}$ number of ANN models where each model is able to predict a specific attribute of the input dataset;

- $\quad$ output processing module: "combiner" of the multiple ANN outputs;

- $\quad$ planogram design based on the output reading.

In the first phase of the project have been defined the input data of the neural network models, by taking into account the information found in the state of the art.

The data processing phase has been structured as follows: 
International Journal on Soft Computing, Artificial Intelligence and Applications (IJSCAI), Vol.7, No.3, August 2018

1. data entry study by adopting appropriate databases as data sources (csv, Excel, MySQL, big data system, etc.);

2. data pre-processing: data pre-processing as choice of fundamental attributes and as data normalization;

3. use of other data mining algorithms useful for output interpretation (classification, clustering, correlation Matrix, association rules, MBA indicators, etc.);

4. development of workflows and scripts related to neural network algorithms (possible use of tools such as Rapid Miner, Orange Canvas, KNIME, Weka or others);

5. optimization of ANN parameters;

6. execution of the ANN models;

7. analysis of the accuracy of the models;

8. output reporting;

9. combination of model outputs and definition of procedures for planogram planning.

The main goal of the project is the definition of procedures suitable to plan a well-structured planogram by combining the results of each individual neural network model. In this paper will be focused the attention on neural network results and on output interpretations representing a part of whole research project

\section{DATASET MODEL AND PRE-PROCESSING}

Below are indicated the attributes of the dataset model used for the neural network processing.

- Mese (last 47 months of sales);

- Azienda (name of the analysed GDO store);

- Incassi (monthly cash of the store);

- N_basso (number of products sold monthly which are positioned down the shelf);

- N_alto (number of products sold monthly which are positioned at the top of the shelf);

- N_Mezzo (number of products sold monthly which are positioned in the central area of the shelf);

- Incassi (cash of monthly sales of all the products of a store);

- Incassi_scaffale (cash of monthly sales of products allocated on the analysed shelf);

- Scontrini (number of receipts pertaining the sale of the products of the whole store);

- N_promotion (product number monthly sold in promotions related the analysed shelf); 
International Journal on Soft Computing, Artificial Intelligence and Applications (IJSCAI), Vol.7, No.3, August 2018

- N_casalinghi (number of household products monthly sold related the analysed shelf);

- N_bibite (number of drinks monthly sold related the analysed shelf);

- N_biscotti (number of biscuits monthly sold related the analysed shelf).

Some attributes are reported in the colour legend of Fig.1. In Fig. 2 is illustrated the experimental dataset.

\begin{tabular}{|c|c|c|c|c|c|c|c|c|c|c|c|c|}
\hline ante & mow & Nens & Namen & $n$ & 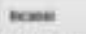 & 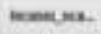 & Cuns & Sunem & Surimat. & neate. & R.anempt & Unasa \\
\hline+ & 1 & $m=00 t$ & $u$ & 4 & nusim & 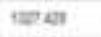 & a & का & s & $n$ & $n$ & " \\
\hline t & 2 & mackbor & as & u & уензанs & visesi & at & tas & 1 & $n$ & $\pi$ & $"$ \\
\hline 3 & 3 & encibor & It & a & esalth & mats & $\mathrm{e}$ & $m$ & 4 & v & $u$ & 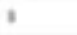 \\
\hline 4 & . & $n=005 t$ & n & as & marm & mast & $n$ & set & w & 1 & 0 & * \\
\hline 8 & 1 & mucosi & a & $\pi$ & setrle & westi & m & tat & $\mathrm{p}$ & $\pi$ & 1 & z \\
\hline 4 & 6 & newder & $a$ & sts & veat at: & tousen & w & stat & n & 1 & $n$ & $n$ \\
\hline $\mathrm{t}$ & , & nestor & a & $D$ & $\operatorname{mens}$ & gevm & a & тан & '. & 11 & v & 2 \\
\hline 4 & 1 & nncior & $\mu$ & a & xeetsan & (тол) & of & vat: & 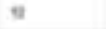 & t. & $n$ & , \\
\hline 4 & 1 & aucbot & 24 & t) & Mastse & antule & $n$ & $\mathrm{~m}$ & $n$ & $*$ & $\pi$ & $n$ \\
\hline 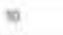 & w & necabt & $n$ & $n$ & Fentse & nasen & $\approx$ & te & * & $n$ & $n$ & , \\
\hline " & $*$ & nestor & $\mathrm{u}$ & 3 & sensw & setis & $=$ & en & $n$ & , & 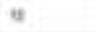 & $a$ \\
\hline te & $u$ & nwCDPt & u & " & soutum & Holate & $\pi$ & זו & $u$ & 1 & * & " \\
\hline n & $\mathrm{n}$ & nuedas & $u$ & 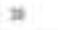 & mans & tentest & of & the & 1 & $n$ & u & $z$ \\
\hline 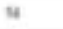 & u & numcos & $\pi$ & $m$ & scsam & $\cos n$ & $\pi$ & $m$ & 1 & $n$ & 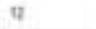 & $n$ \\
\hline$\leqslant$ & 5 & mestopt & a) & " & sertan & $\operatorname{cm} 2 \pi$ & $\pi$ & ts & 1 & n & 1 & 45 \\
\hline$=$ & $*$ & Ancibur & 4 & y & sen: & mens & w & 20 & 1 & $u$ & $u$ & 13 \\
\hline$\pi$ & $\pi$ & mestost & $n$ & $z$ & Itwien & tament & $\pi$ & $m$ & 1 & $n$ & os & , \\
\hline " & v & nuscor & $n$ & 21 & avtum & gan & बा & $m$ & 1 & $\pi$ & " & $n$ \\
\hline$=$ & 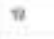 & mectobr & II & 14 & esatise & 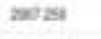 & $=$ & 200 & ' & $\pi$ & $\pi$ & \#E \\
\hline$=$ & $a$ & mesopt & $n$ & , & สะมนท & काल & $=$ & wes & , & $n$ & 4 & $n$ \\
\hline si & 24 & nescovt & 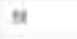 & $\mathrm{x}$ & rean & 1192 & ta & tos & $*$ & $n$ & $v$ & t \\
\hline z & w & neckior & u & t) & atitia & ten2.5i & $\mathrm{E}$ & $n e$ & 15 & 16 & F. & 4 \\
\hline nt & n & muebot & u & $z$ & sthus & $m a t$ & $=$ & $m$ & 1 & $\mu$ & 4 & $n$ \\
\hline$x$ & a & $n m 0001$ & I & $\pi$ & sent & onare & $\mathbf{m}$ & ato & 1 & $n$ & $n$ & 6 \\
\hline s & a & necibot & st & $n$ & sansa & $1725+5$ & $=$ & $=0$ & i & $\mathrm{t}$ & H & $*$ \\
\hline in & a & mostar & $n$ & at & sexum & What & $=$ & $\mathrm{ni}$ & ? & , & I & + \\
\hline
\end{tabular}

Figure 2. Experimental dataset made by 47 records loaded into RapidMiner local repository.

A first analysis is performed a pre-processing by plotting the product sold in the different shelf position. As illustrated in Fig. 3 it is evident that the products allocated in the central part of the shelf are the most sold while the products placed in the top of the shelf are the less sold. 


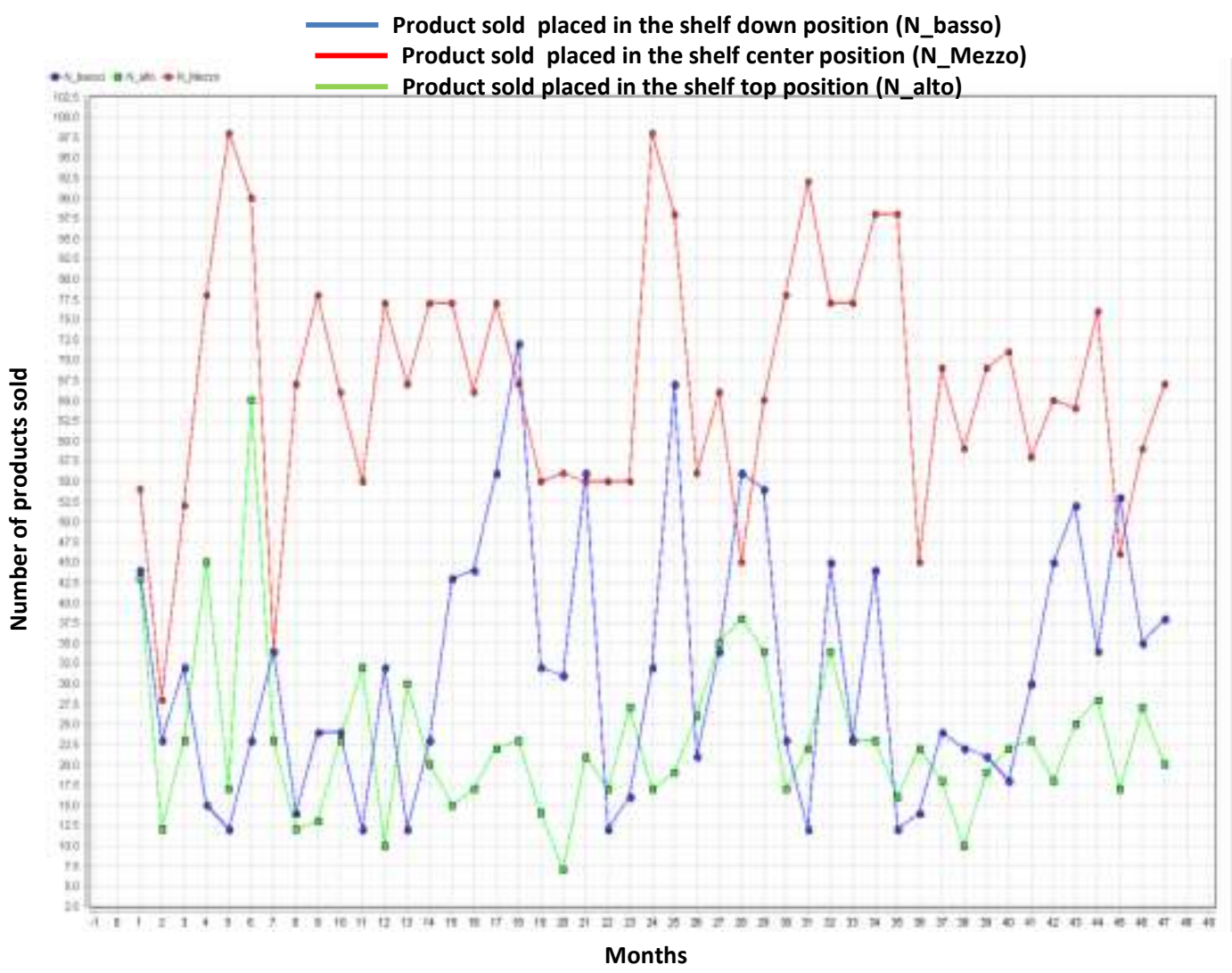

Figure 3. Analysis of the products sold in the last 47 months related to different shelf layout positions.

These graphical results highlights the importance of the central position in the VM strategy. For the pre-processing has been applied the correlation data mining algorithm by means of the "Correlation Matrix" module of RapidMiner tool shown in Fig. 4. A correlation is a number between -1 and +1 that measures the degree of association between two Attributes (call them $\mathrm{X}$ and $\mathrm{Y}$ ). A positive value for the correlation implies a positive association. In this case large values of $X$ tend to be associated with large values of $Y$ and small values of $X$ tend to be associated with small values of $Y$. A negative value for the correlation implies a negative or inverse association. In this case large values of $X$ tend to be associated with small values of $Y$ and vice versa. The outputs of the Correlation Matrix algorithms is illustrated in the table of Fig. 4. By means of the data correlation pre-processing analysis it is possible to observe that there is an high positive correlation between the total number of receipts of the store and the receipts associated with the analyzed shelf: this proves that the visual impact of the analyzed shelf provided good results. The table of Fig. 4 indicates also that there is a significant correlation $(0.3)$ between the number of shelf drinks sold and receipts. Another important correlation (0.258) is checked between N_biscotti and N_Mezzo attributes: this means, for example, that the biggest sale of biscuits happens when products are placed in the center of the shelf. Finally it is observed a slight correlation between N_Mezzo and N_promozione attributes, thus showing that the products available at the center are those usually in promotions. 


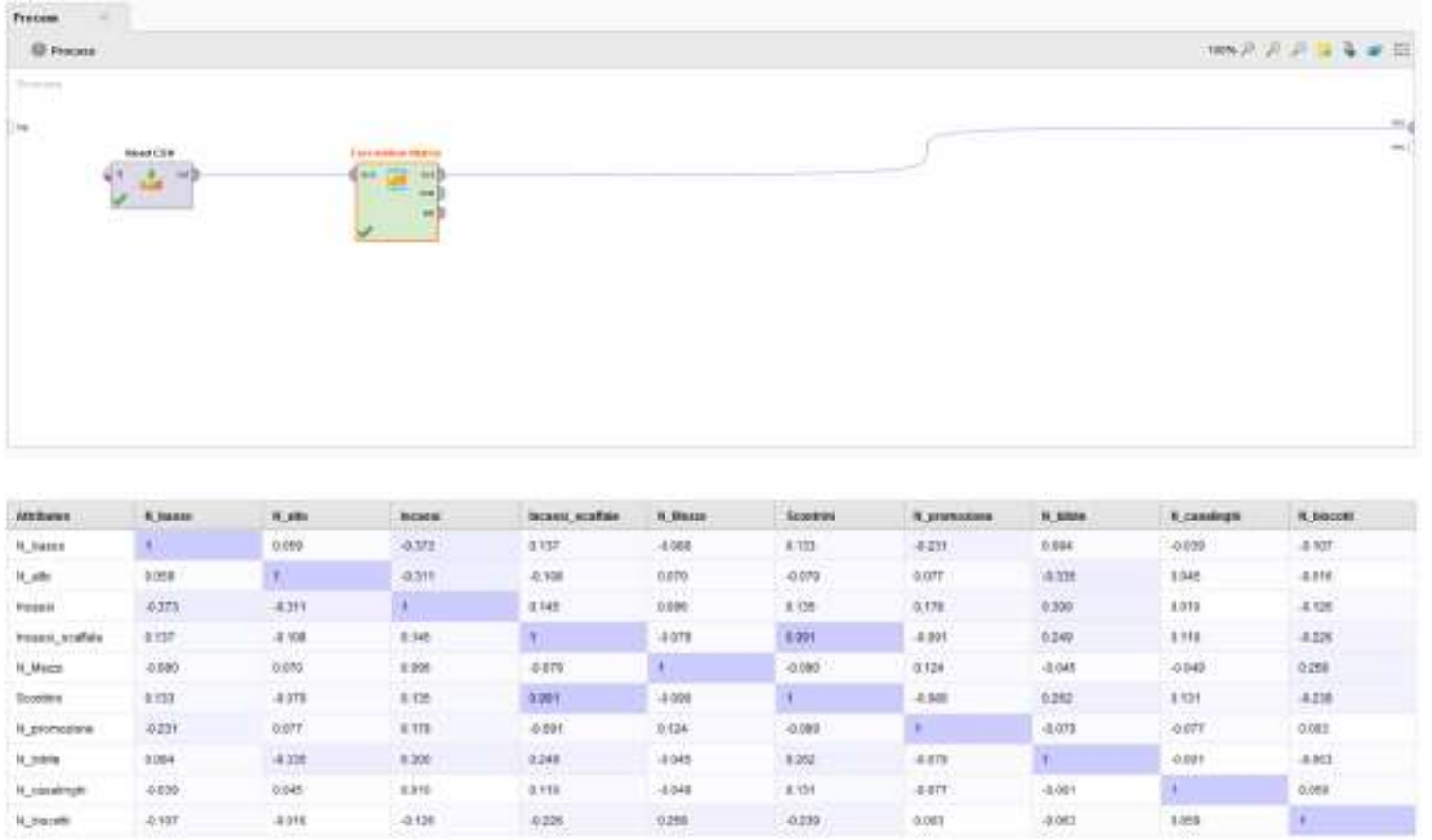

Figure 4. (Above) "Correlation Matrix” module of RapidMiner. (Below) correlation matrix results.

\section{WEKA NEURAL NETWORK MODEL DEVELOPMENT AND RESULTS}

The models performed in this section are implemented in java language by using Eclipse platform, and ANN Weka libraries. The models are based on time series forecasting with Multilayer Perceptron -MLP- classifier [22]-[23]. A MLP represents a class of feedforward ANN, consisting of at least three layers of nodes implementing a supervised learning technique called backpropagation for training. Except for the input nodes, each node is a neuron that uses a nonlinear activation function. All the predictive models proposed in this section have been performed by an algorithm proposed in [22] which exhibits good performances and matching with experimental values [22].

The first model is related to the prediction of cash related to a single GDO store. In Fig. 5 are illustrated the monthly cash values and the first 6 predicted cash values (up to the 47th month are data measured, from the 48th to 53th are the predicted values).

As example we report below a part of the main class java script concerning the attribute selections of "Incassi" (cash) and "Mese" (month):

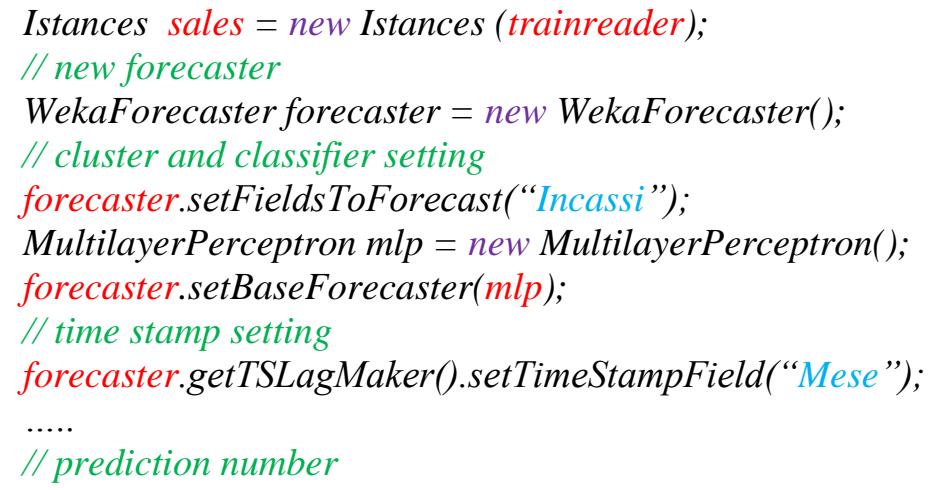


int steps $=6$;

Observing value amplitudes of Fig. 4 it is possible to note that only the first three value matches with possible certain values. The other three predicted samples could provide only an uncertain predicted values (anomalous amplitudes if compared with store cash monthly values).

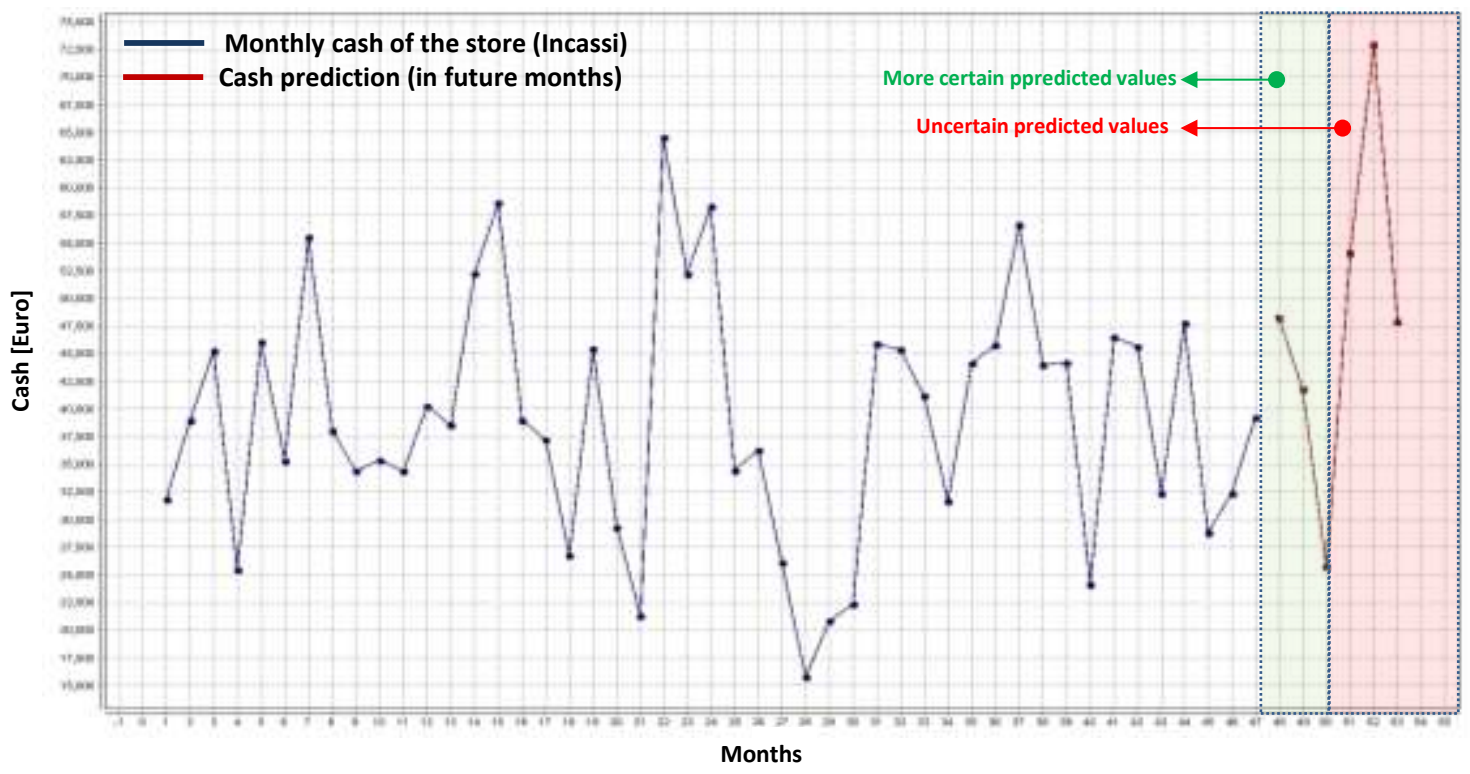

Figure 5. Weka model 1: prediction results.

The model 2 focus the attention on the cash related to a single analyzed shelf. In this case is considered the forecast prediction of 24 months, obtaining the results of Fig. 6. From Fig. 6 it is observed a regular trend behavior of cash that continues approximately for each 12 months. For this case only the first four predictive results are more certain.

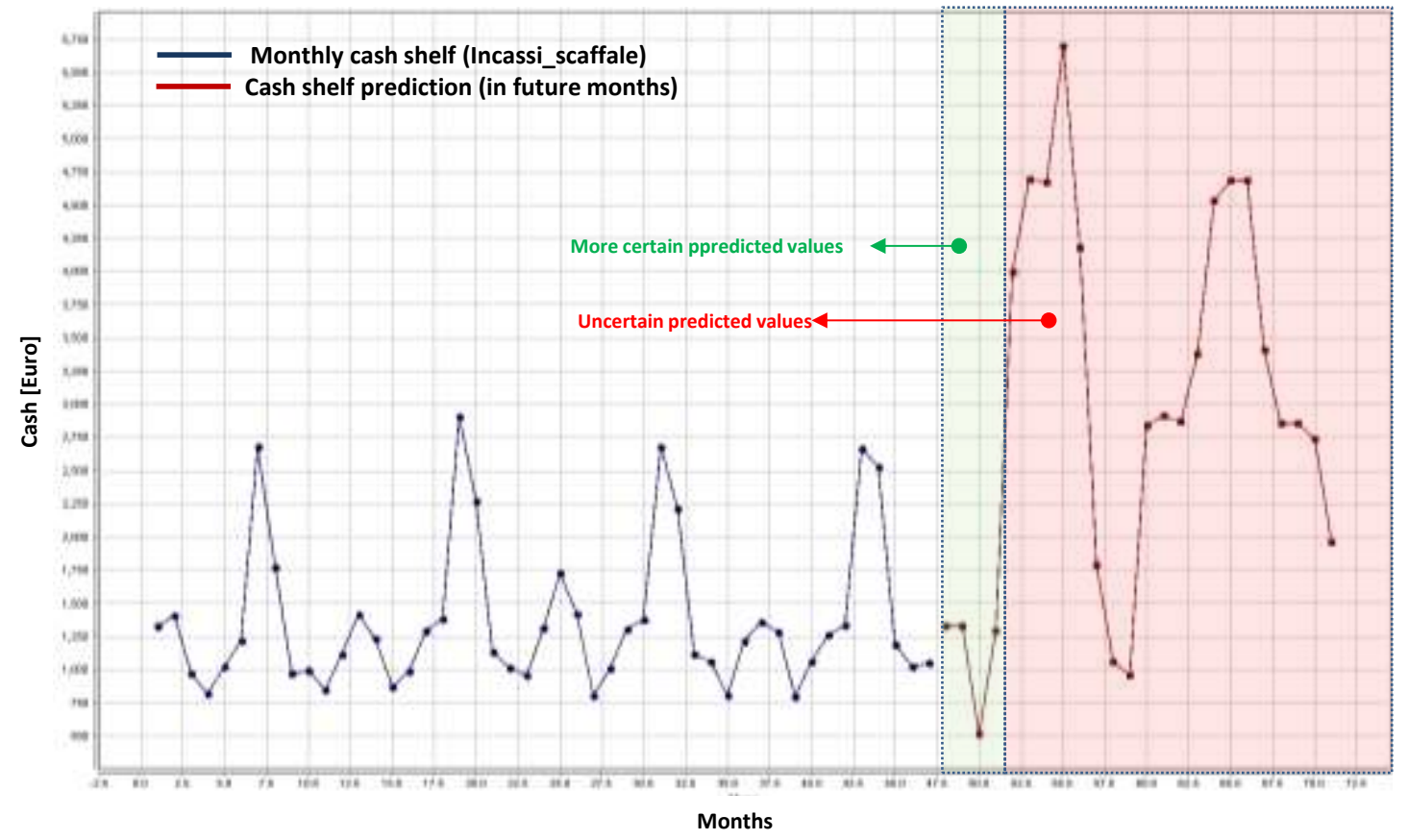

Figure 6. Weka model 2: prediction results. 
International Journal on Soft Computing, Artificial Intelligence and Applications (IJSCAI), Vol.7, No.3, August 2018

In the model 3 of Fig. 7 are illustrated the output results of the MLP ANN algorithm applied to the receipt number prediction: as for the previous model also in this case is observed a regular trend, and only the first five predictive results are more certain.

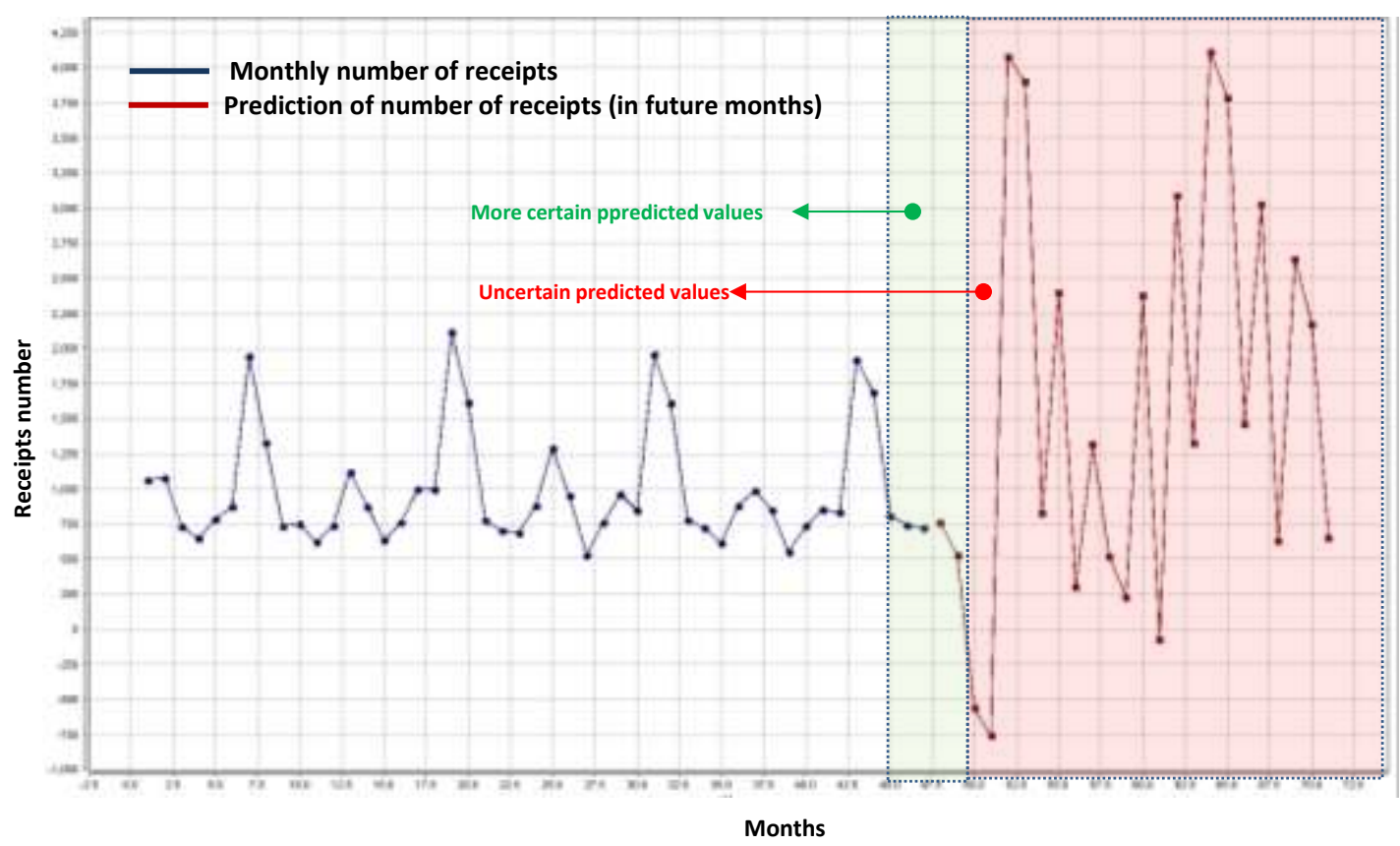

Figure 7. Weka model 3: prediction results.

In the model 4 of Fig. 8 are illustrated the predictive sales pertaining to the products positioned at the top of the analyzed shelf. In this case it is observed a certain convergence of the solution for the first 4 predicted months.

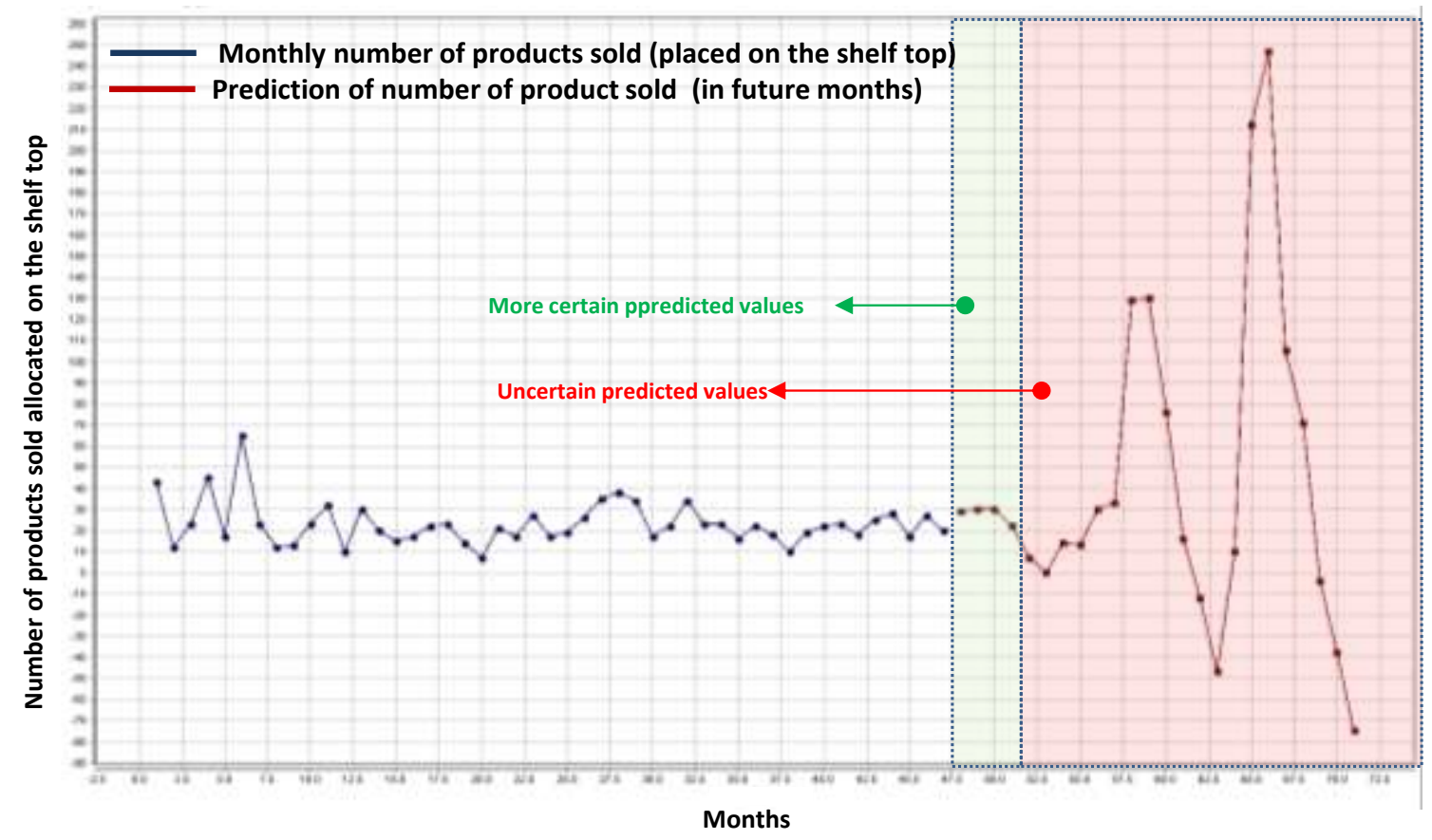

Figure 8. Weka model 4: prediction results. 
International Journal on Soft Computing, Artificial Intelligence and Applications (IJSCAI), Vol.7, No.3, August 2018

By the model 5 it is estimated the sales prediction of products placed on the shelf down part: the first predicted four values of the irregular trend enhances an initial increase of the quantity of products followed by a fast decrease.

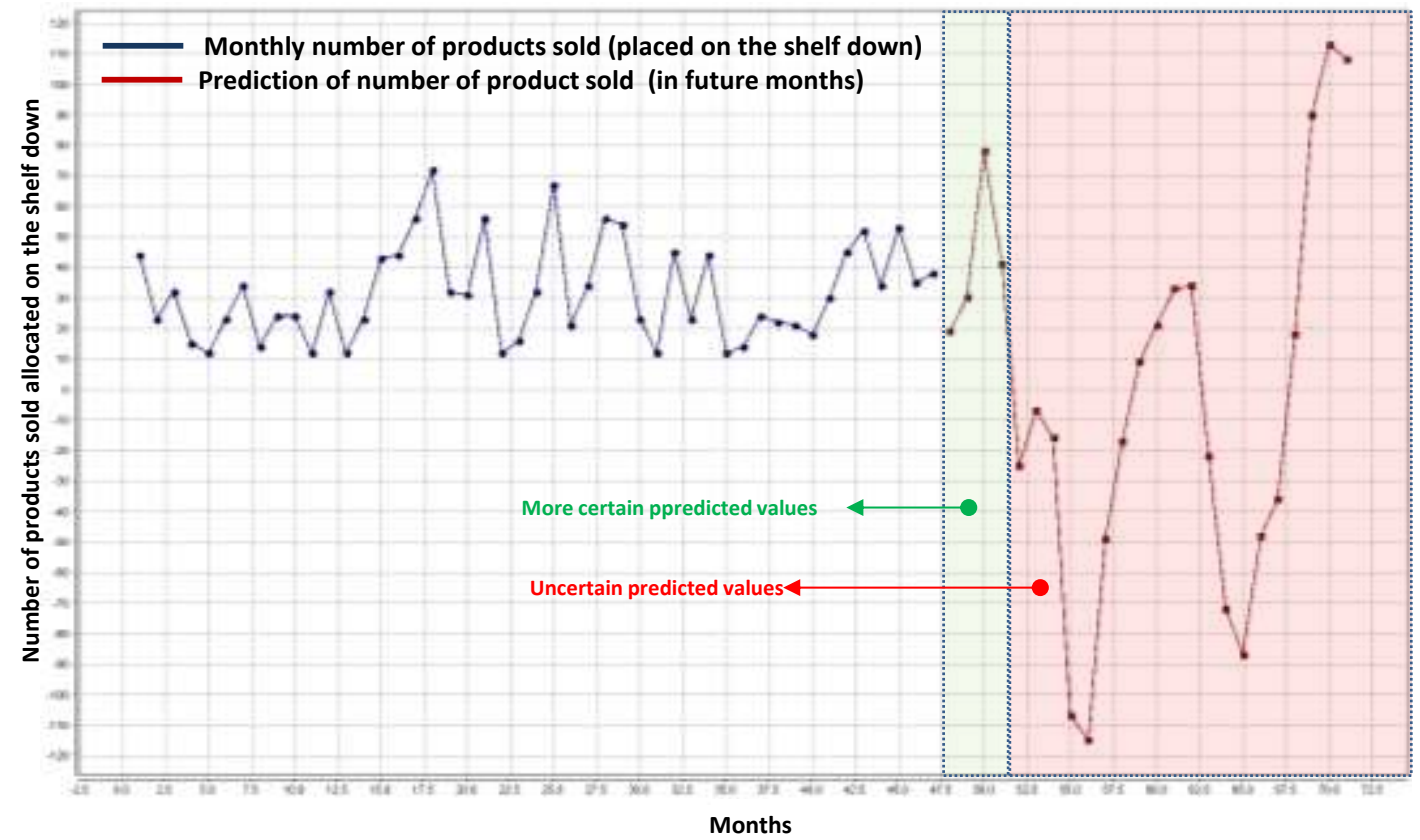

Figure 9. Weka model 5: prediction results.

The predictive results of model 6 shows the prediction of the product that will be sold if placed on the middle part of the shelf, where only the first two predicted values are trusted.

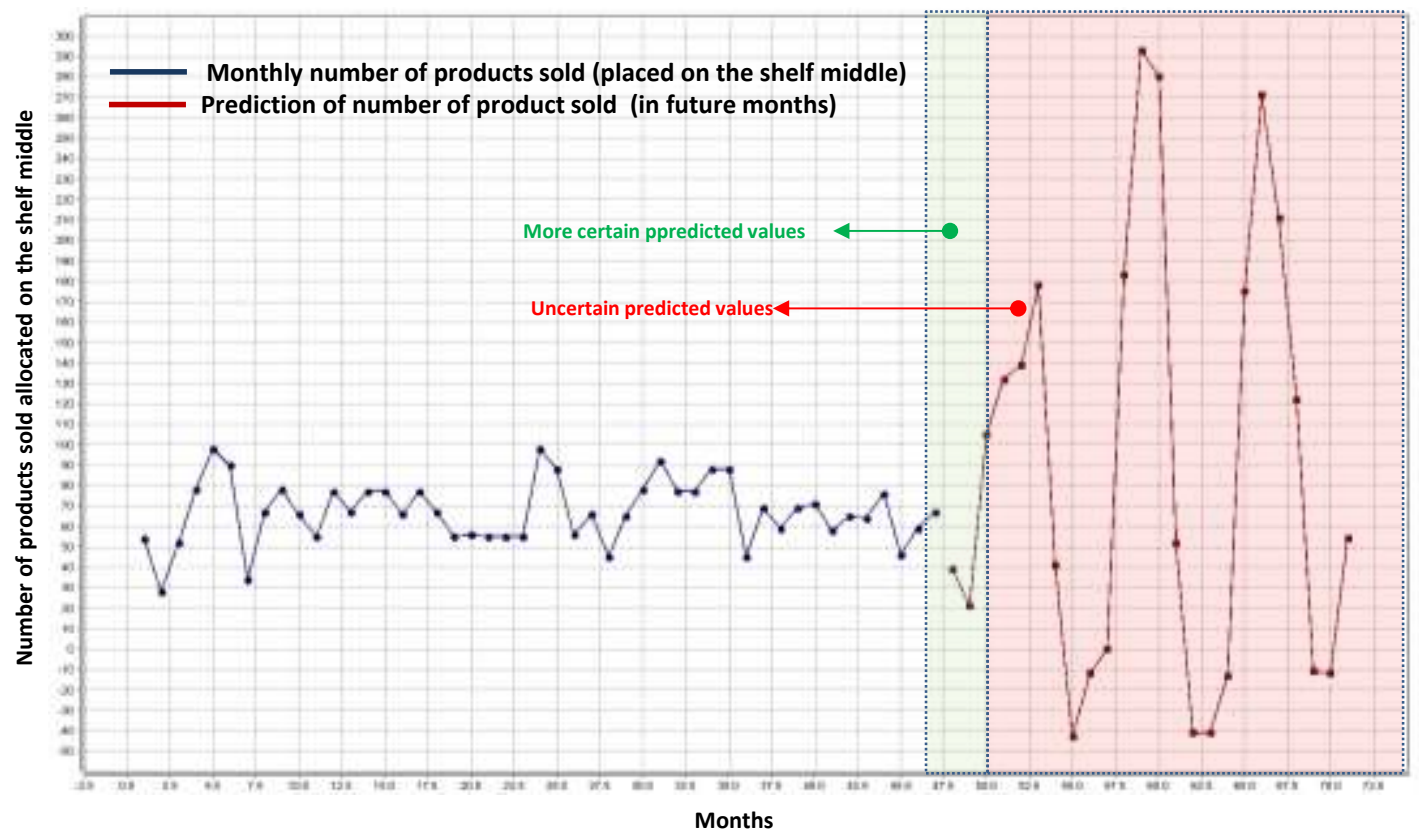

Figure 10. Weka model 6: prediction results.

Finally model 7 (Fig. 11), model 8 (Fig. 12) and model 9 (Fig. 13) indicate the sales prediction of drinks, of household products and of biscuits placed in the middle of the shelf, respectively. 


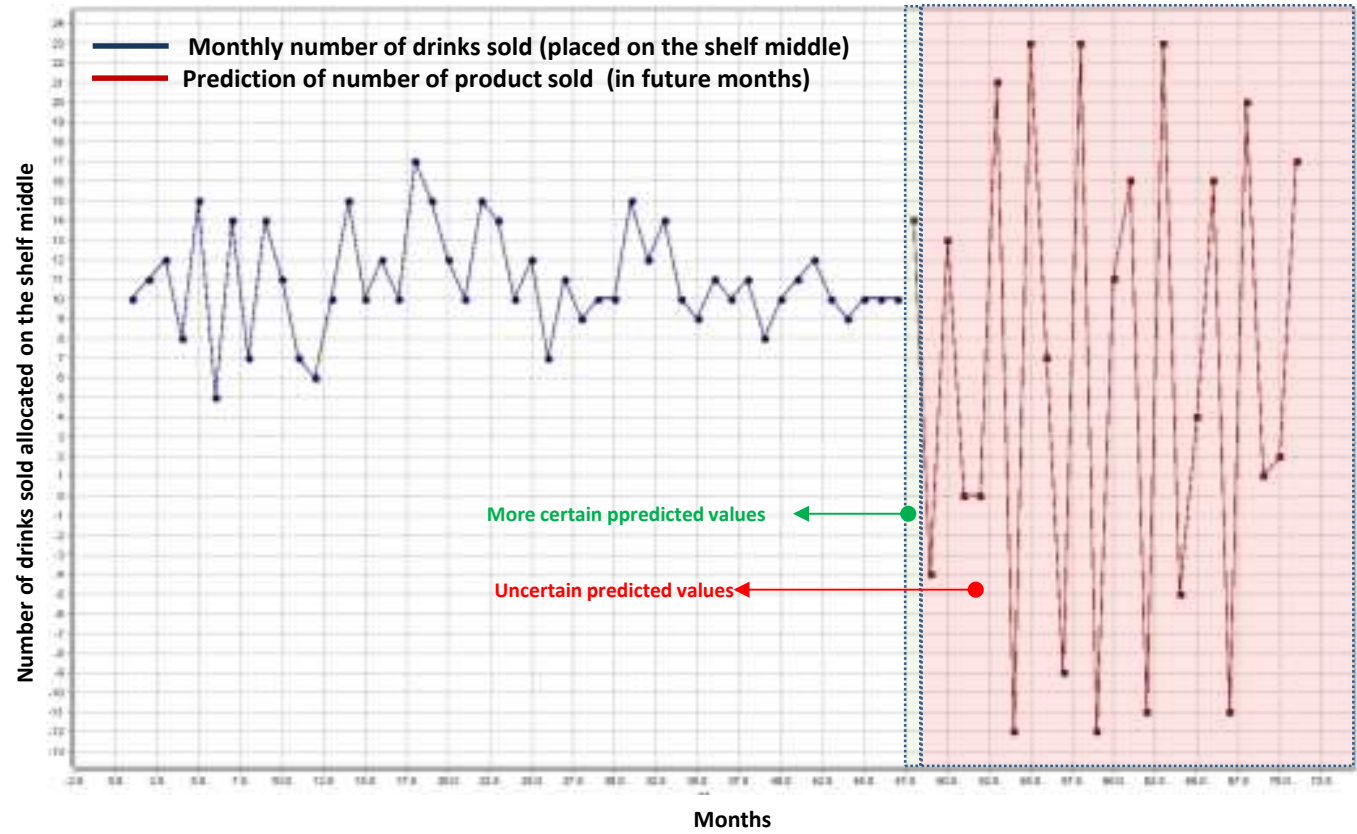

Figure 11. Weka model 7: prediction results.

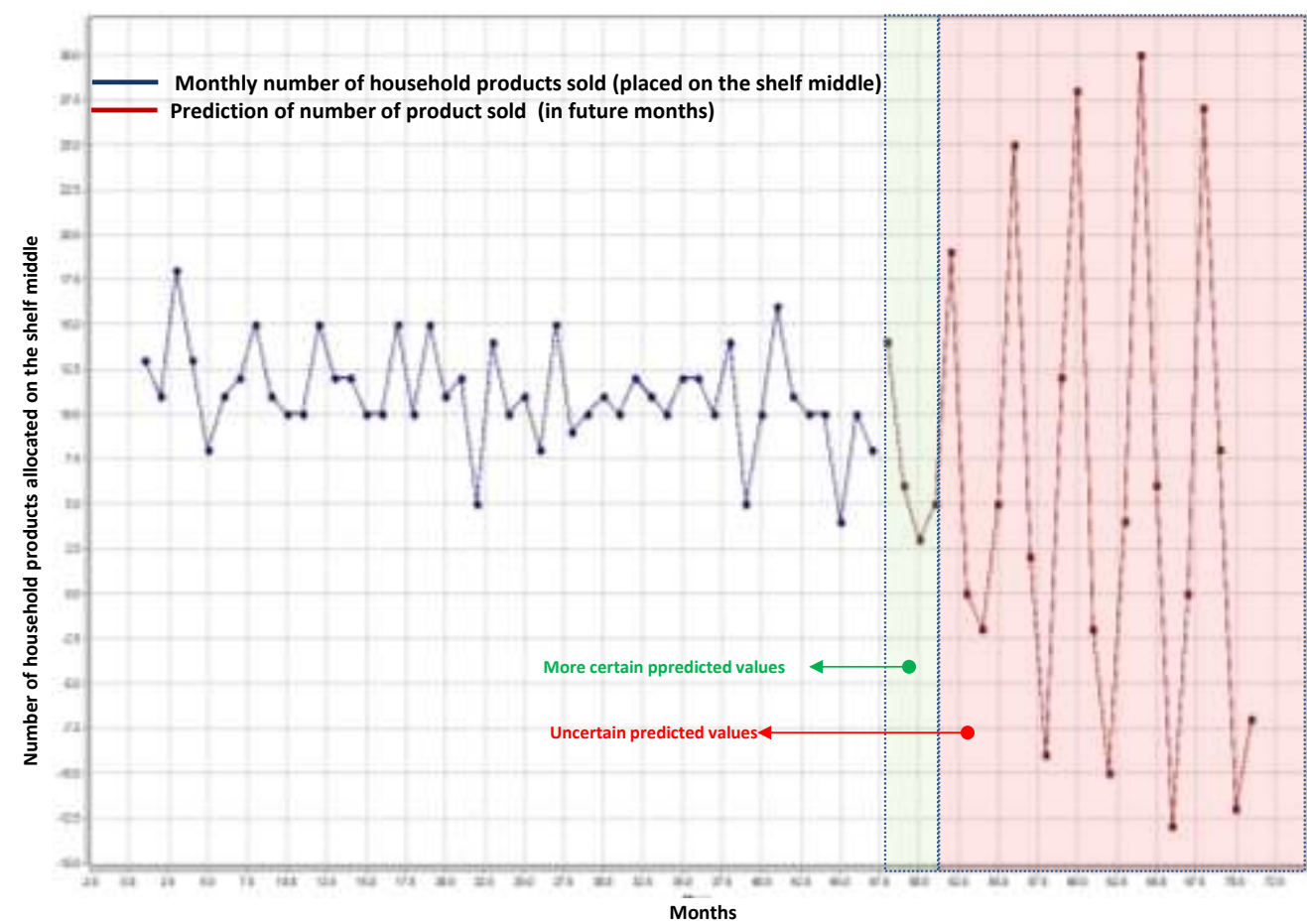

Figure 12. Weka model 8: prediction results. 


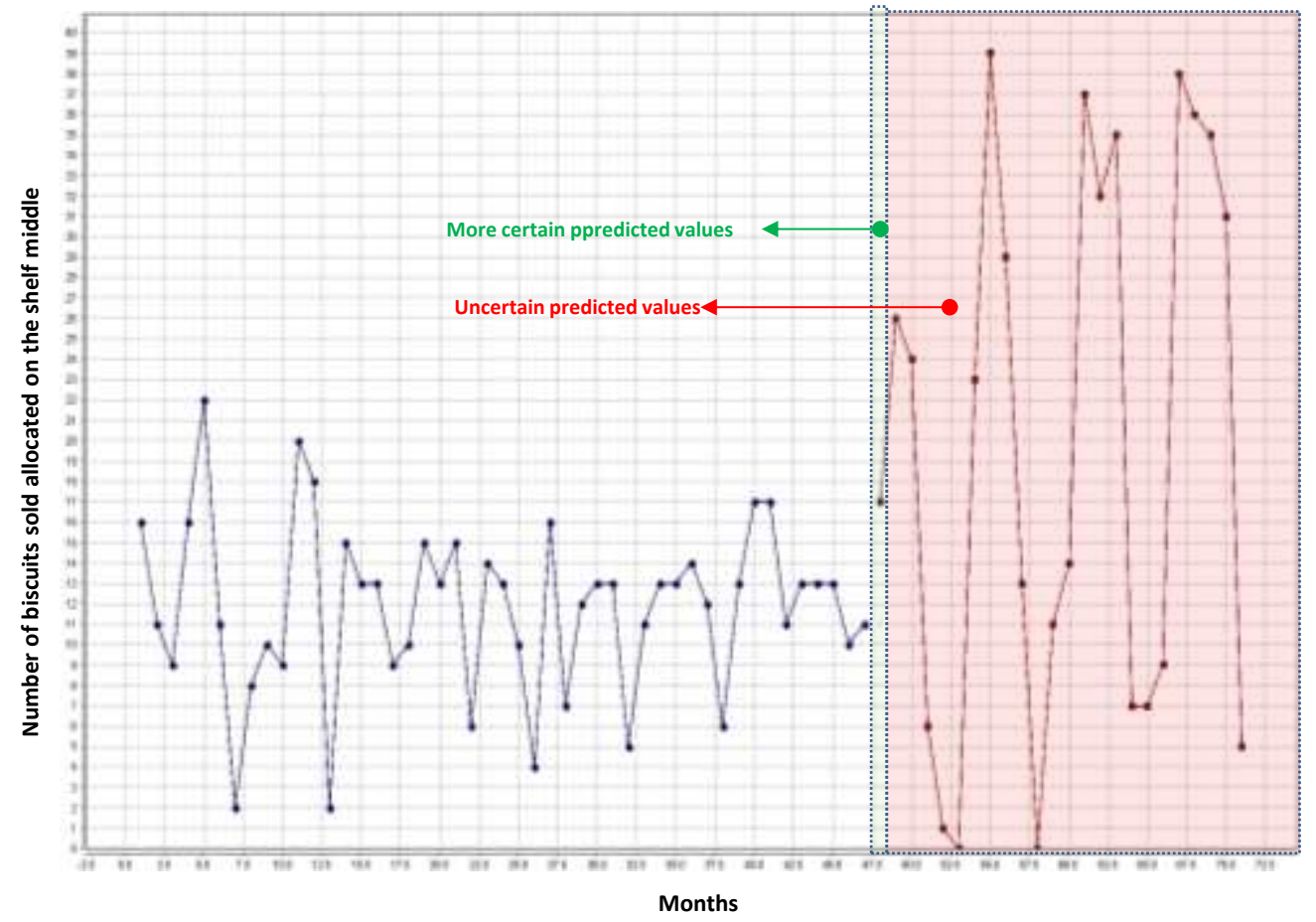

Figure 13. Weka model 9: prediction results.

For all the plots of Weka results have been applied the RapidMiner Scatter Multiple function, and the "Append" object able to plot the predicted results (red lines) after the real ones (blue lines). All the models have been executed by setting the following best parameters: learning rate of 0.3 , momentum of 0.2 , training time of 500, validation set size equals to zero, seed equals to zero, and hidden layers equals to (number of attributes + classes) $/ 2$.

In order to estimate the variability of the results have been executed different predictions by changing the learn rate parameter $\mathrm{L}$, observing that the learning rate of $\mathrm{L}=0.3$ represents a good compromise between convergent solutions and low variability (see Fig. 14). We observe that the learning rate is one of the most important hyper-parameters to tune for training deep neural networks [24]. The definition of the its optimum value will increase the prediction accuracy [24]. 


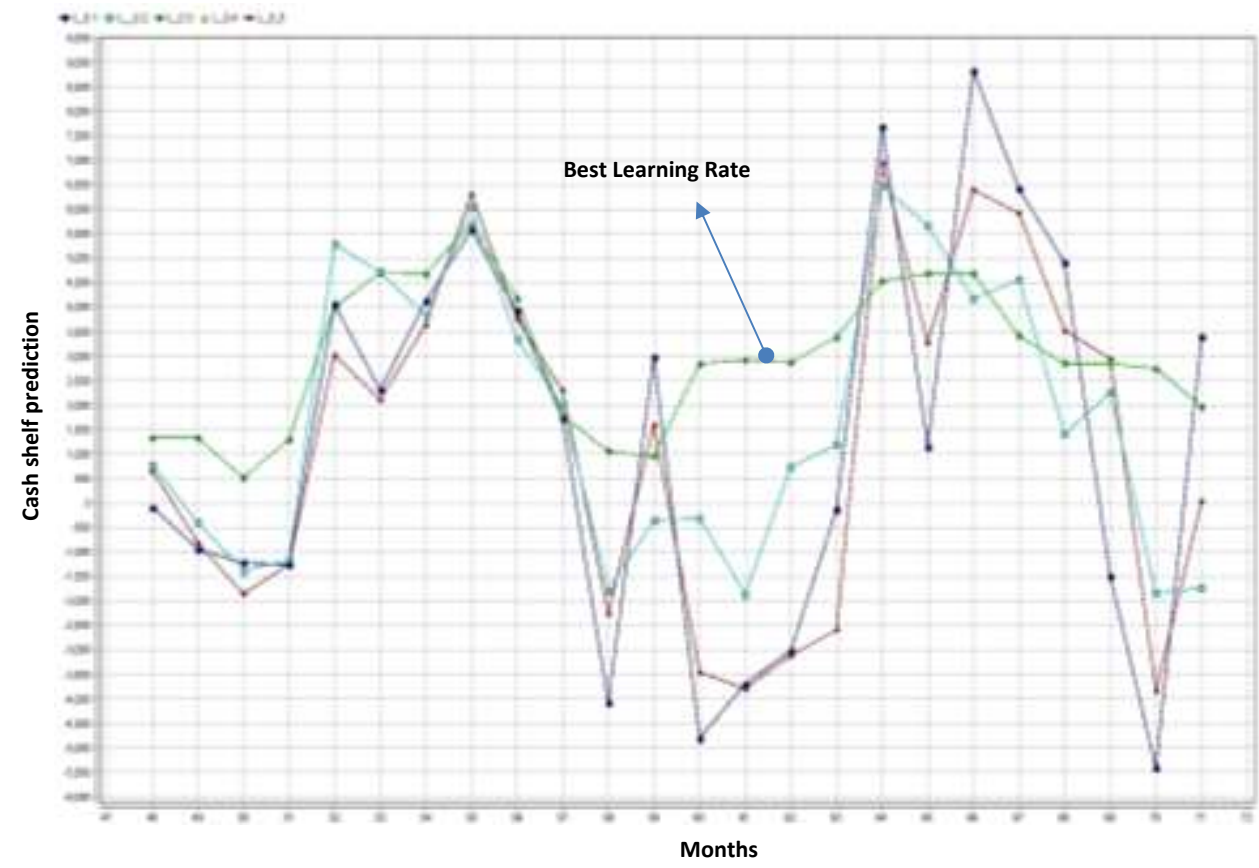

Figure 14. Weka: choice of the best learning rate indicating a slower oscillation response versus months.

All the first predicted values of the proposed Weka predictive models indicate the more certain values. In table 1 are summarized these first values representing with green color the increase trend and with the red color the decrease one.

\begin{tabular}{|l|l|l|l|}
\hline Attribute & $\begin{array}{l}\text { Last value (47 } \\
\text { th month) }\end{array}$ & $\begin{array}{c}\text { First predicted value } \\
\text { (48 th month) }\end{array}$ & $\begin{array}{c}\text { Increase/ decrease } \\
\text { trend }\end{array}$ \\
\hline Cash & 39209 & 48166 & \\
\hline Shelf cash & 1050 & 1325 & \\
\hline Receipts & 722 & 758 & \\
\hline Down shelf & 38 & 19 & \\
\hline Top shelf & 20 & 29 & \\
\hline Middle shelf & 67 & 39 & \\
\hline Promotion & 7 & 25 & \\
\hline Household & 8 & 14 & \\
\hline Drinks & 10 & 14 & \\
\hline Biscuits & 11 & 17 & \\
\hline
\end{tabular}

Table 1: increase/decrease trend.

The results of table 1 show that only the two attributes indicated with the red color will suffer a decrease in sales. Let's now define some useful observations for planogram design based on the results displayed during the simulations. For a better forecasting and shelf planning will be considered only the initial trend. The products placed in down and middle part of the shelf will be characterized by a decrease: being the promotion correlated with products allocated in down shelf region (see table of Fig. 4), a corrective action could be to promote these products. Also the products placed in middle could be promoted. The products positioned at the top, as they are expected to increase their sales, could be repositioned in the last position. The last position could also be maintained for household products, biscuits and drinks. Another solution could be to move some biscuits or drinks or household products in the middle to leave the space to other products. In any case, a greater turnout of customers and a greater total cash-out are expected, so 
International Journal on Soft Computing, Artificial Intelligence and Applications (IJSCAI), Vol.7, No.3, August 2018

that promotional activities could be applied in a non-strong way. Furthermore, even if the current shelf configuration is maintained, there will be a relevant increase of shelf cash, so it is not recommended even to make large movements.

\section{RAPID MINER NEURAL NETWORK MODEL : AN ALTERNATIVE MLP ANN MODEL}

MLP ANN developed by RapidMiner workflow are applied in industrial research [25]. The use of objects constituting a workflow facilitates the execution of the MLP ANN algorithms simply setting parameters by graphical user interfaces - GUIs-. In Fig. 15 is illustrated the RapidMiner workflow applied for sales prediction. The developed model has been performed on the ANN network layout reported in Fig. 16 having a single hidden layer configuration.

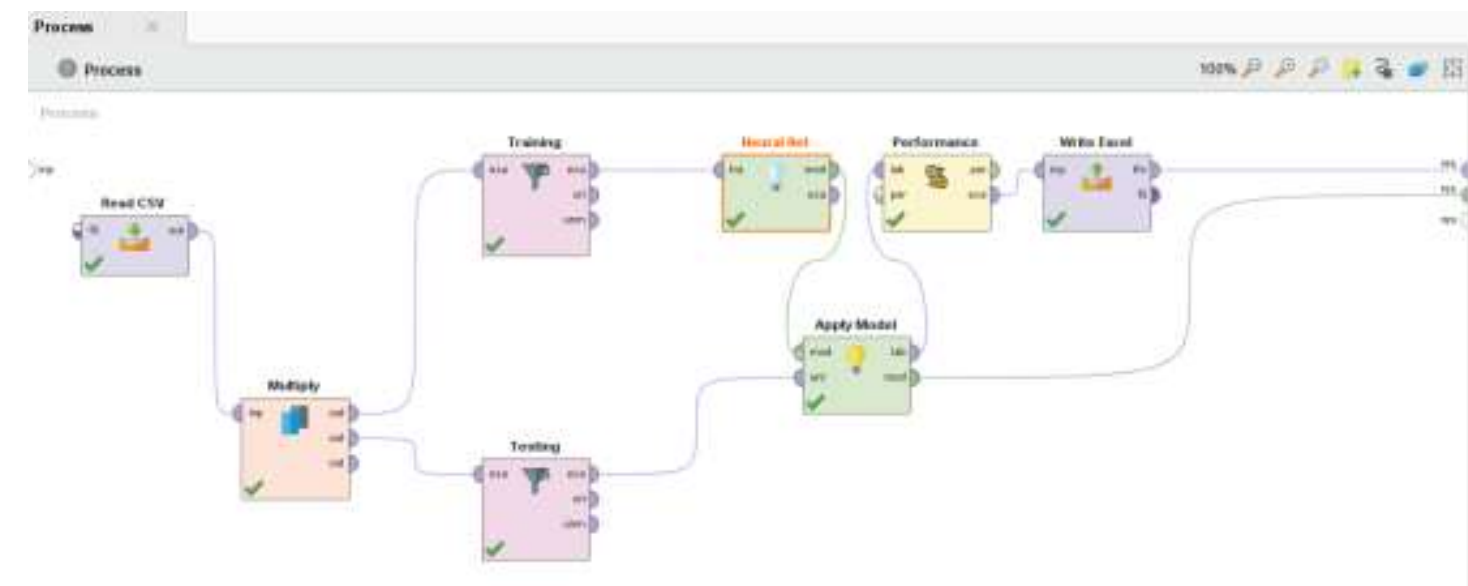

Figure 15. RapidMiner workflow implementing MLP ANN.

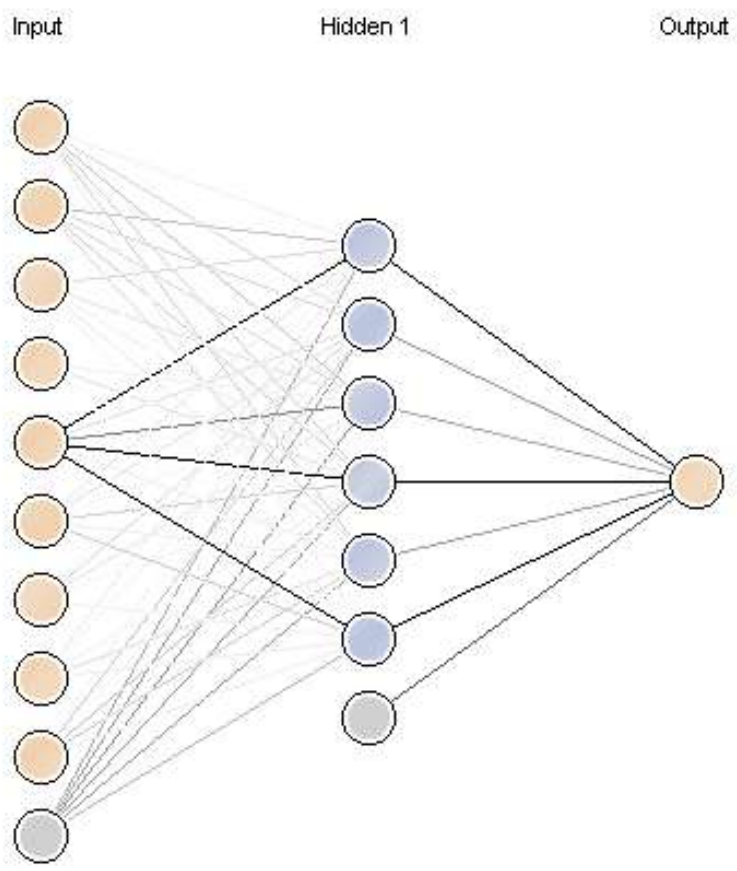

Figure 16. RapidMiner: MLP ANN layout. 
The RapidMiner MLP ANN model is applied on cash prediction in order to propose an alternative model, by providing the results of Fig. 17 with a good performance: an absolute error of only (62.925 Euro +/- 52.898 Euro is checked).

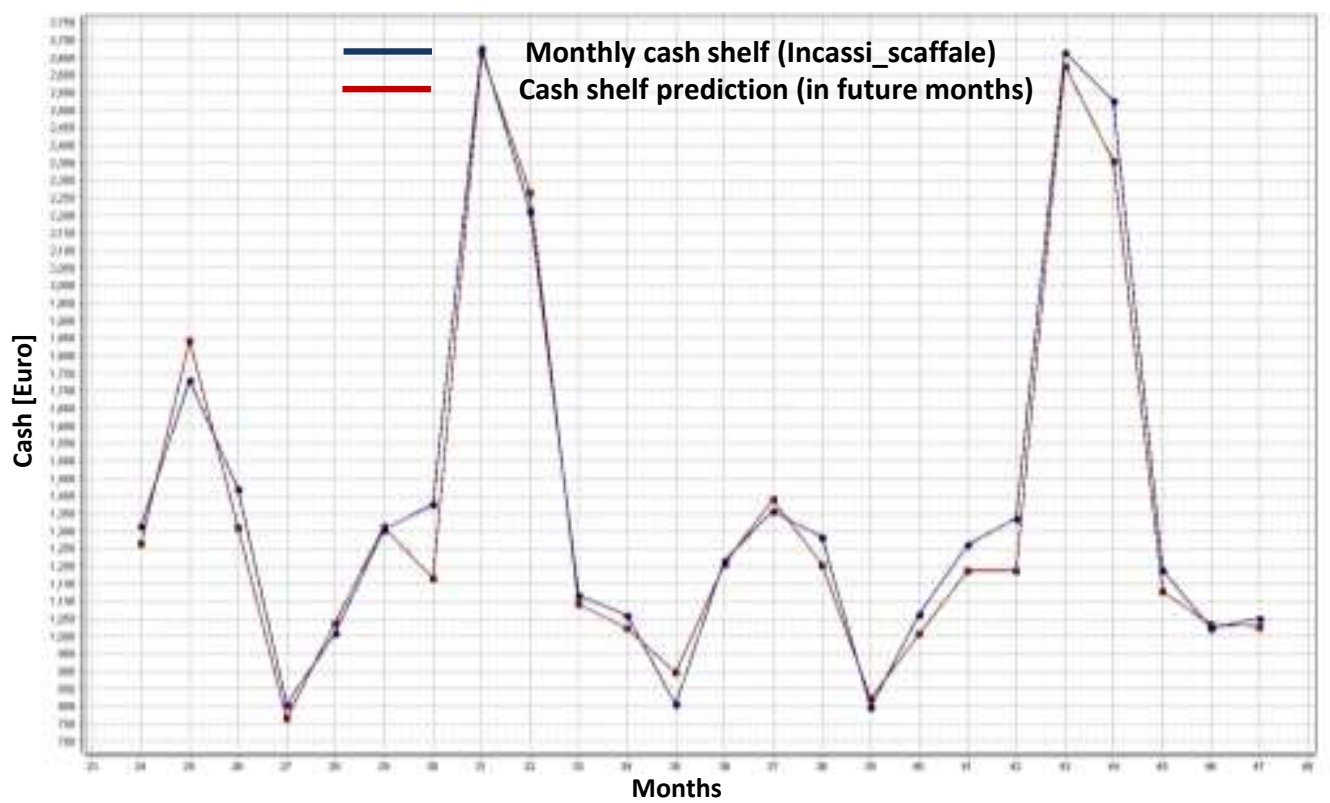

Figure 17. RapidMiner: comparison between real values of the last monthly cash shelf and predicted ones.

The model of Fig. 15 has been applied also for the prediction of the drink sales by achieving an absolute error of $1.253+/-1.074$ (see Fig. 18). These data processing models prove that RapidMiner could be a good alternative to apply the models previously discussed.

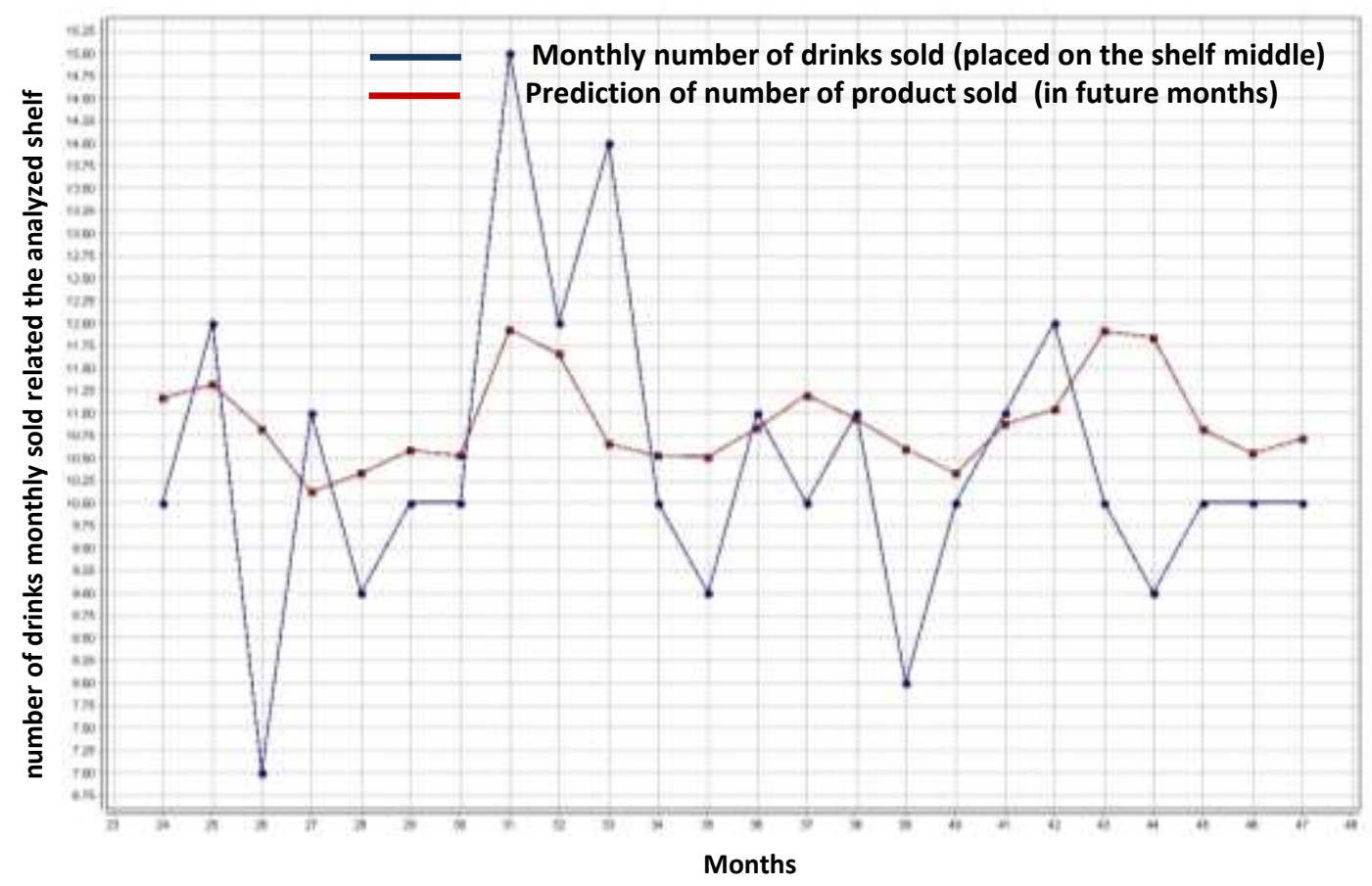

Figure 18. RapidMiner: comparison between real values of the last monthly cash shelf and predicted ones. 
International Journal on Soft Computing, Artificial Intelligence and Applications (IJSCAI), Vol.7, No.3, August 2018

By observing the last real values in blue color of Fig. 17 and Fig. 18, and the first ones of the prediction indicated by the red color, it is observed a good matching with results indicated in table 1: in both case an initial increase is checked.

\section{INNOVATIVE RAPIDMINER AND WEKA HYBRID MODEL}

The performance of the MLP ANN algorithms could be optimized by constructing an hybrid model involving Weka and RapidMiner algorithms. This approach is useful for cases characterized by an experimental dataset made by few records thus allowing to accelerate the self learning process. In Fig. 19 is illustrated the innovative hybrid model designed as a merge of Weka and RapidMiner MLP ANN algorithms: the initial training and testing dataset are the input data of the Weka models described in section IV, besides the RapidMiner workflow will process the initial training dataset and, as testing, will process the output of the Weka algorithm.

(b)
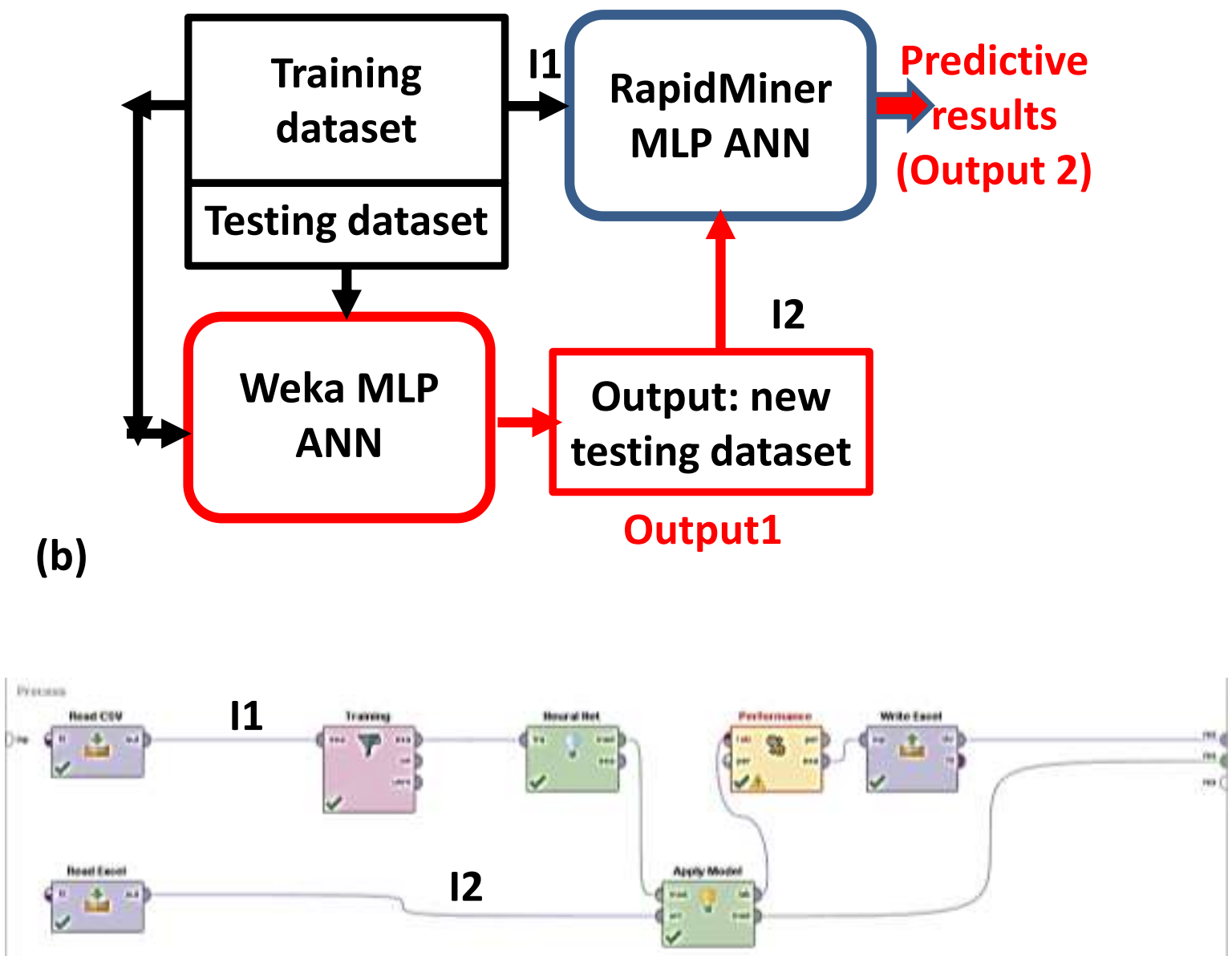

Figure 19. Innovative flow chart: (a) hybrid Weka/RapidMiner model optimizing experimental dataset, (b) RapidMiner workflow implementing the hybrid model.

By executing the flowchart of Fig. 19 (a) and Fig. 19 (b) for the prediction of drinks placed on the shelf middle, are obtained the outputs results of Fig. 20, where output 1 indicates the outputs of the Weka algorithm, and output 2 are the final predicted values of the RapidMiner workflow model of Fig. 19 (b). We observe that also using testing dataset having a strong oscillation, the final output results are characterized by a lower amplitude of oscillation. 


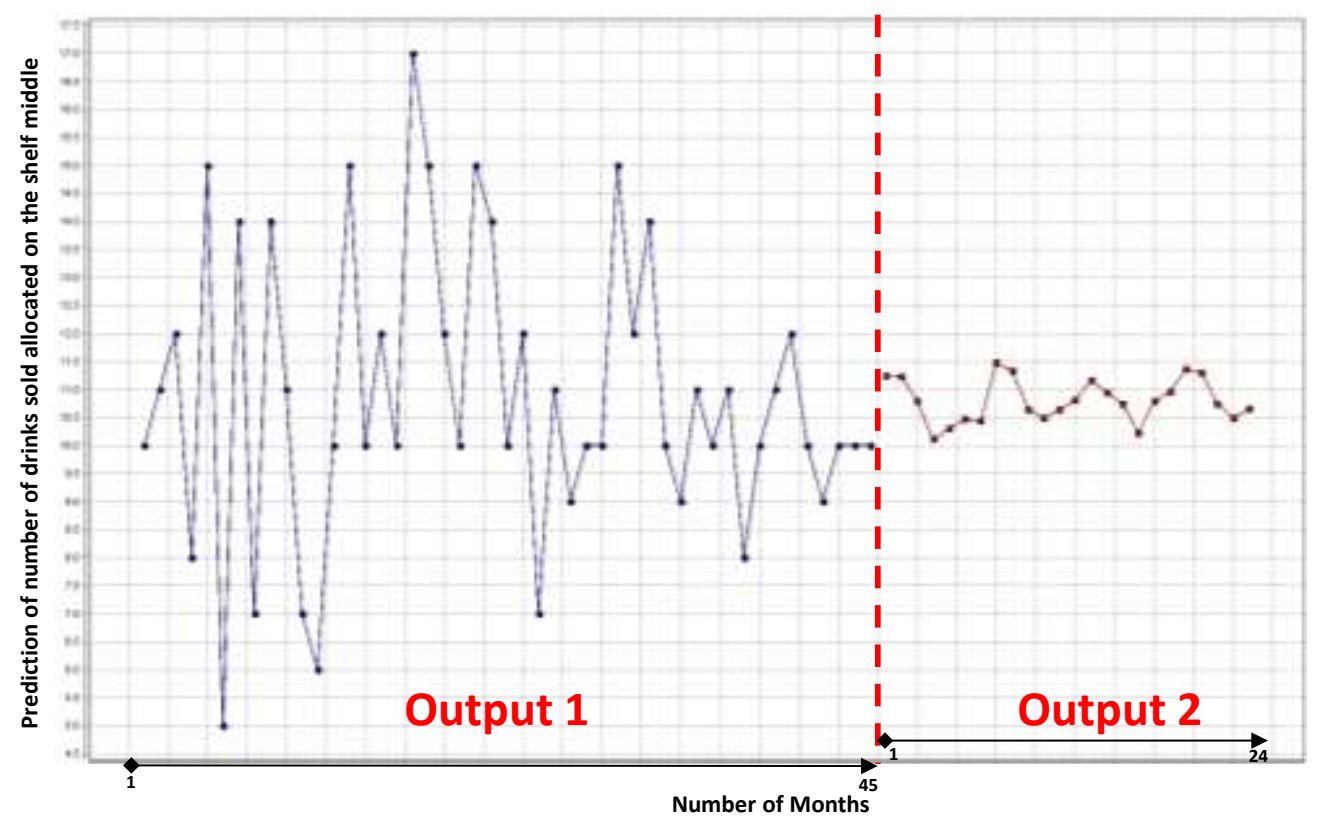

Figure 20. Hybrid model outputs: output of the Weka predictive model (output 1), and output of the final values predicted by the RapidMiner algorithm (output 1). Months 1 refers to the first predicted values.

The comparison results of Fig. 21 highlights that the output of proposed hybrid model is convergent to the previous one shown in Fig. 15, thus confirming that it is possible to increase the initial experimental dataset in order to accelerate the self learning process by adding an "artificial" testing dataset which is an output of another prediction MLP ANN model.

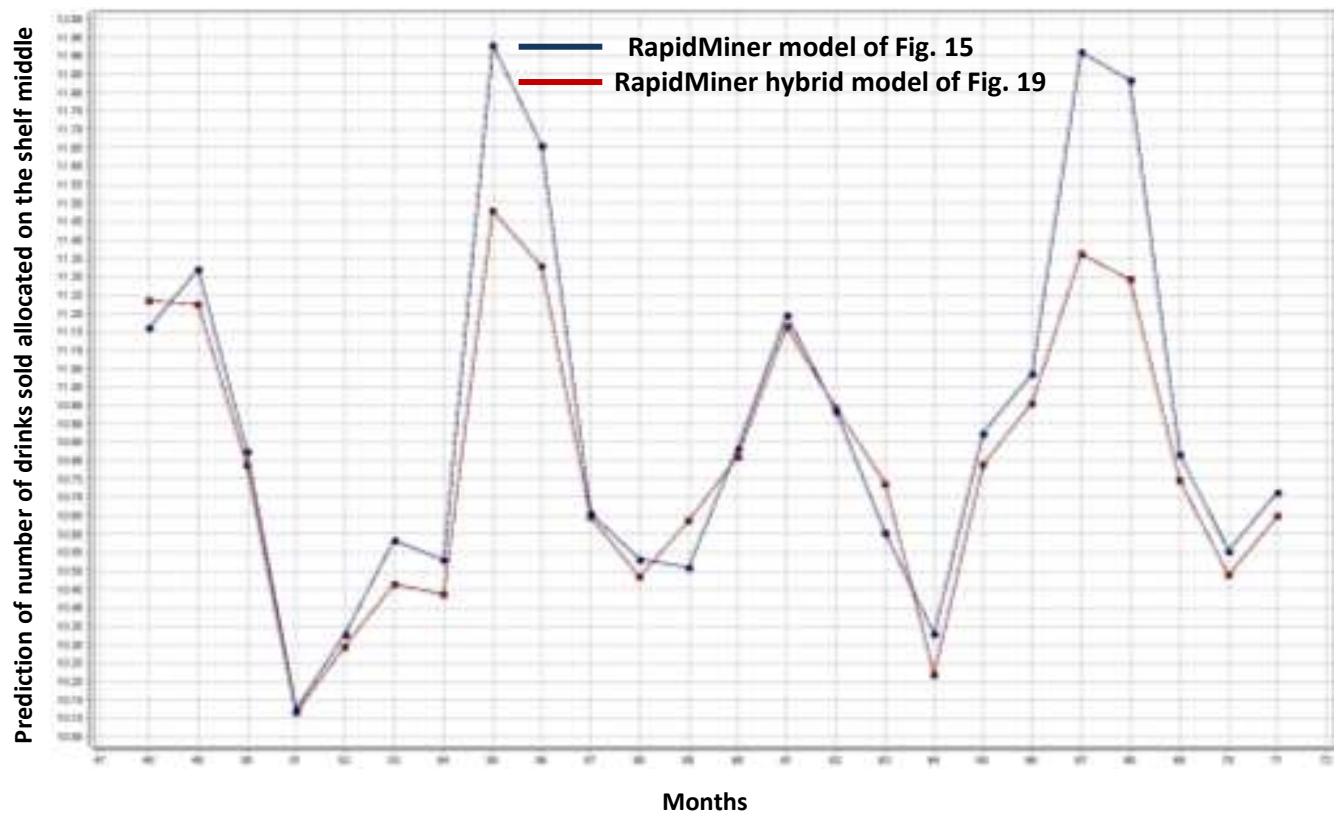

Figure 21. Hybrid model output: comparison of the outputs of the hybrid model of Fig. 19, with the outputs of the model of Fig. 15. 


\section{Conclusion}

The goal of the paper is the formulation of a model composed by a multiple MLP ANN networks applied in GDO sales prediction. Each MLP ANN network is able to predict sales by analysing a specific attribute. The experimentation is focused on the analysis of products allocated on a supermarket shelf by providing solutions for planogram design. The prediction results are related of total sales of a store and of sales related a testing shelf, by differentiating the analysis of some attributes such as products placed on the top, middle and down part of the shelf, products in promotions, and different kind of product typologies. A preliminary analysis showed some important relationships and correlations between attributes useful for the outputs interpretation and for the planogram design. Weka MLP ANN algorithms have been adopted for the prediction of the initial trend of the products allocated on the testing shelf. RapidMiner MLP ANN models have been indicated as alternative performing approaches. Finally has been proposed an hybrid model integrating both WEKA and RapidMiner algorithms implemented in this paper. This last model is suitable for self learning approaches processing a dataset of few sample.

\section{ACKNOWLEDGEMENTS}

The work has been developed in the frameworks of the Italian projects: "Modelli di Visual Merchandising mediante Reti Neurali: "Neural Net Visual Merchandising" [Neural Networks Models of Visual Merchandising: "Neural Net Visual Merchandising"]. Authors gratefully thanks the researchers D. Barbuzzi, G. Birardi, V. Calati, L. D’Alessandro, F. De Carlo, A. Leogrande, O. Rizzo, M. Solazzo, and M. M. Sorbo for their support in the realization of this work.

\section{REFERENCES}

[1] Bastow-Shoop, H. E., Zetocha, D. F. \& Passewitz, G. (1991) "Visual Merchandising- A guide for Small Retailers", Editor: North Central Regional Center for Rural Development, Iowa State University of Science and Technology.

[2] Krafft, M., \& Mantrala, M. K. (2010) "Retailing in the 21st Century- Current and Future trends-," Springer book.

[3] Katrandjiev, H. \& Velinov, I. (2015) "Optimization of Online Visual Merchandising Elements (OVME) on the Basis of Consumer Preferences," Economic Alternatives, Vol. 2, pp76-88.

[4] Lee, J., Hoch, R., Podlaseck, M., Schonberg, E. \& Gomory, S. (2000) "Analysis and Visualization of Metrics for Online Merchandising", Chapter, Web Usage Analysis and User Profiling, Volume 1836 of the series Lecture Notes in Computer Science, pp126-141.

[5] Rajagopal, S. (2011) "Customer Data Clustering Using Data Mining Technique", International Journal of Database Management Systems (IJDMS), Vol.3, No.4, pp1-11.

[6] Horská, E., Mehl, H. \& Berík, J., (2014) "Review of Classical and Neuroscience Insights on Visual Merchandising Elements and Store Atmosphere", Proceedings from IX. International Conference on Applied Business Research ICABR 2014, pp284-290.

[7] Tao, J., Teng, N., Poh, H.-L. \& Tan, C. L. (1998) "Forecasting and Analysis of Marketing Data Using Neural Network", Journal of Information Science and Engineering, Vol. 14, No. 4, pp523-545.

[8] Di Persio, L. \& Honchar, O. (2016) "Artificial Neural Networks Approach to the Forecast of Stock Market Price Movements", International Journal of Economics and Management Systems, Vol. 1, pp158-162.

[9] Khan, Z. H. ,Alin, T. S. \& Hussain, A. (2011) "Price Prediction of Share Market using Artificial Neural Network (ANN)", International Journal of Computer Applications (0975 - 8887), Vol. 22, No.2, pp4247.

[10] Yao, J., Teng, N., Poh, H.-L. \& Tan, C. L. (1998) "Forecasting and Analysis of Marketing Data Using Neural Networks", Journal of Information Science and Engineering, Vol. 14, No. 4, pp523-545.

[11] Rygielski, C., Wang, J.-C. \& Yen, D. C. (2002) "Data Mining Techniques for Customer Relationship Management", Technology in Society, Vol. 24, No.4, pp483-502. 
[12] Doganis, P., Alexandridis, A., Patrinos, P., Sarimveis, H. (2006) "Time Series Sales Forecasting for Short Shelf-Life Food Products Based on Artificial Neural Networks and Evolutionary Computing", Journal of Food Engineering, Vol.75, No.2, pp196-204.

[13]Murray, C. C. (2010) "Joint Optimization of Product Price, Display Orientation and Shelf-Space Allocation in Retail Category Management," Journal of Retailing, Vol. 86, No. 2, pp125-136.

[14] Van Nierop, E., Fok, D. \& Franses, P. H. (2008) "Interaction Between Shelf Layout and Marketing Effectiveness and its Impact on Optimizing Shelf Arrangements", Marketing Science, Vol. 27, No. 6, pp1065-1082.

[15] Kotler, P. \& Zaltman, G. (1971) "Social Marketing: An Approach to Planned Social Change", Journal of Marketing, Vol. 35, No. 3, pp3-12.

[16]Chen, M.-C. \& Lin, C.-P. (2007) "Data Mining Approach to Product Assortment and Shelf Space Allocation", Expert Systems with Applications, Vol. 32, No. 4, pp976-986.

[17] Dixon, M., Klabjan, D. \& Bang, J. H. (2016)"Classification-Based Financial Markets Prediction using Deep Neural Networks", Algorithmic Finance.

[18] Ansari, A. \& Riasi, A. (2016) "Modelling and Evaluating Customer Loyalty Using Neural Networks: Evidence from Startup Insurance Companies", Future Business Journal, Vol.2, No.1, pp15-30.

[19] Navale, G. S., Dudhwala, N., Jadhav, K., Gabda, P. \& Vihangam, B. K. (2016) "Prediction of Stock Market using Data Mining and Artificial Intelligence", International Journal of Computer Applications, Vol. 134, No.12, pp9-11.

[20] Borimnejad, V. \& Samani, R. E. (2016) "Modeling Consumer's Behavior for Packed Vegetable in 'Mayadin Management Organization of Tehran' Using Artificial Neural Network", Cogent Business \& Management, Vol. 3, pp1-14.

[21] Massaro, A., Galiano, A., Barbuzzi, D., Pellicani, L., Birardi, G., Romagno, D. D. \& Frulli, L. (2017) "Joint Activities of Market Basket Analysis and Product Facing for Business Intelligence Oriented on Global Distribution Market: Examples of Data Mining Applications", (IJCSIT) International Journal of Computer Science and Information Technologies, Vol. 8, No.2, pp178-183.

[22] Massaro, A., Galiano, A., Meuli, G. \& Massari, S. F. (2018) "Overview and Application of Enabling Technologies Oriented on Energy Routing Monitoring, on Network Installation and on Predictive Maintenance", International Journal of Artificial Intelligence and Applications (IJAIA), Vol. 9, No. 2, pp1-20.

[23] Kumar, R. \& Balara, P. (2014) "Time Series Forecasting of Nifty Stock Market Using Weka", JRPS International Journal for Research Publication \& Seminar, Vol. 5, No. 2, pp1-6.

[24] Peace, I. C., Uzoma, A. O. \& Ita A. A. (2015) "Effect of Learning Rate on Artificial Neural Network in Machine Learning", International Journal of Engineering Research \& Technology, Vol. 4, No. 2, pp359-363.

[25] Massaro, A. \& Galiano, A. (2018) "Design and Development of a Mobile APP for Multichannel Sales Systems based on Artificial Intelligence", (IJCSIT) International Journal of Computer Science and Information Technologies, Vol. 9, No. 3, pp63-68.

\section{Corresponding Author}

Alessandro Massaro: Research \& Development Chief of Dyrecta Lab s.r.l.

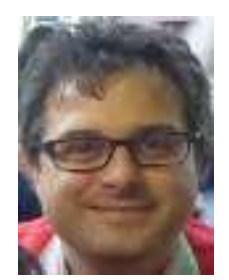

